\title{
UK Renal Registry 16th Annual Report: Chapter 7 Demography of the UK Paediatric Renal Replacement Therapy population in 2012
}

\author{
Rishi Pruthi ${ }^{a}$, Catherine O’Brien ${ }^{b}$, Anna Casula ${ }^{a}$, Fiona Braddon ${ }^{a}$, Malcolm Lewis ${ }^{c}$, \\ Heather Maxwell ${ }^{d}$, Jelena Stojanovic ${ }^{e}$, Yincent Tse ${ }^{f}$, Carol Inward $^{g}$, Manish D Sinha ${ }^{e}$ \\ aUK Renal Registry, Bristol, UK; 'Birmingham Children's Hospital, Birmingham, UK; 'Manchester Children's Hospital, \\ Manchester, UK; ${ }^{d}$ Royal Hospital for Sick Children (Yorkhill), Glasgow, UK; ${ }^{E}$ Evelina Childrens Hospital, London, UK; \\ ${ }^{f}$ Royal Victoria Infirmary, Newcastle, UK; ${ }^{9}$ Bristol Royal Hospital for Children, Bristol, UK
}

\section{Key Words}

Aetiology Children · Demography $\cdot$ End stage renal disease . Established renal failure - Incidence · Prevalence · Ethnicity - Renal replacement therapy · Survival

\begin{abstract}
Introduction: To describe the demographics of the paediatric renal replacement therapy (RRT) population under the age of 18 years in the UK and to analyse changes in demography with time. Methods: Data were collected from all 13 paediatric renal centres within the UK. A series of crosssectional and longitudinal analyses were performed to describe the demographics of paediatric RRT patients. Results: A total of 861 children and young people under 18 with established renal failure (ERF) were receiving treatment at paediatric nephrology centres in 2012. At the census date, $80.2 \%$ had a functioning transplant, $10.6 \%$ were receiving haemodialysis (HD) and $9.2 \%$ were receiving
\end{abstract}

peritoneal dialysis (PD). In patients aged $<16$ years the prevalence of ERF was 56.7 pmarp and the incidence 9.0 pmarp. A third of the prevalent patients had one or more reported comorbidities. At transfer to adult services, $81.5 \%$ of patients had a functioning renal transplant. Preemptive transplantation was seen to occur in a third of children starting RRT under 16 years, with lower rates seen in girls and ethnic minorities. Over the past 15 years for those referred early, there has been a rise in pre-emptive transplantation rates, rising from $26.2 \%$ in 1998-2002 to $36.3 \%$ in 2008-2012. Over the same period there has also been an increase in living donation from $7.1 \%$ to $18 \%$. Survival in childhood amongst children starting RRT was the lowest in those aged less than two years. Conclusions: The findings of this report are similar to last year with continued improvement in data quality and electronic submission of data returns. The data provided in this report show slowly increasing trends of incidence and prevalence in children with established renal failure.

\section{KARGER}

Fax +4161306 1234 E-Mail karger@karger.com www.karger.com 


\section{Introduction}

Established renal failure (ERF) requiring renal replacement therapy (RRT) is a rare but significant cause of long term morbidity and mortality during childhood, with specialist care being provided in 13 paediatric nephrology centres in the UK. All centres are equipped to provide peritoneal dialysis and haemodialysis, with ten centres also undertaking kidney transplantation for children. In the United Kingdom (UK) in 2011, the prevalence rate of treated ERF in children aged under 16 years was 56.8 and the incidence rate was 8.3 per million age related population (pmarp).

The objectives of this report are:

(i) To describe the UK prevalence, incidence, causes of ERF and modality of treatment of children on RRT on 31st December 2012

(ii) To describe trends of the same over the past 15 years, and

(iii) To describe pre-emptive transplantation rates and survival of children on RRT aged $<16$ years old in the UK.

\section{Methods}

Data collection was performed by all 13 paediatric nephrology centres managing children on RRT in the UK in 2012. Most centres submitted data electronically to the UK Renal Registry (UKRR) with only two centres submitting data using paperbased data returns this year. These data items were then manually entered into the current paediatric UKRR database. Thus $92 \%$ of data returns including 791 of 861 children were performed electronically in 2012.

In this report, patient groups are described as: (i) 'prevalent' group: patients who were receiving RRT on the 31st December 2012; (ii) 'incident' group: patients who started RRT between 1st January and 31st December 2012; and (iii) '5 year' groups: patients who started RRT in the periods of 1998-2002, 20032007 and 2008-2012.

The populations used to calculate the incidence and prevalence rates were obtained from the Office for National Statistics (ONS) [1]. The mid-2012 population estimate produced by the ONS, based on the 2011 Census, was used for calculating the 2012 incident and prevalent group rates; the 2001 Census data was used for the 1998-2002, 2003-2007 and 2008-2012 '5 year' groups.

Infants under the age of three months and 'late presenters' (defined as children commencing dialysis within three months following review by a paediatric nephrologist) were excluded from analyses when calculating pre-emptive transplantation rates. For survival analysis, only patients starting RRT between 1st January 1998 and 31st December 2011 were included to ensure a minimum of 1 year follow up at the census date, and were followed up to a maximum age of 16 years.

\section{Statistical analyses}

Statistical analyses were performed using SAS 9.3, with group analyses using Chi-square test and median analyses using Kruskal-Wallis test. A Cox regression model was used in calculating hazard ratios for patient survival, adjusting for gender, age at start of RRT, and RRT modality as a time dependent variable. Survival probabilities were calculated using univariate Kaplan Meier curves.

\section{Results}

\section{Accuracy and completeness of data returns}

Efforts to improve the overall accuracy of the entire paediatric dataset by clinical teams, data managers and statisticians over these past few years have resulted in improved accuracy of the database, analyses and conclusions. The data returns, now showing near 100\% data completeness being achieved by all centres for a range of data items including, gender, ethnicity, treatment modality and age at start of RRT. Data completeness for other core items was better than previous reports and is shown in table 7.1 [2].

The UK paediatric prevalent ERF population in 2012

A total of 861 children and young people under 18 years with ERF were receiving treatment at paediatric nephrology centres in 2012. At the census date, $80.2 \%$ had a functioning kidney transplant, $10.6 \%$ were receiving haemodialysis (HD) and $9.2 \%$ were receiving peritoneal dialysis (PD).

Patients aged 16-18 years may receive their medical care either in a paediatric or in an adult nephrology centre. As data were incomplete for the 16-18 year old adolescent patients, they have been excluded from the majority of subsequent analyses (particularly when describing incidence and prevalence rates).

There were 679 children under 16 years of age receiving RRT in the UK in 2012. Table 7.2 shows the number of patients receiving RRT by age group and gender plus rate of RRT pmarp. The prevalence of RRT increased with age and was higher in males across all age groups with an overall male to female prevalence ratio of 1.5. The reported prevalence rate in under 16 year olds was 56.7 pmarp.

Table 7.3 shows the ethnic origin of current RRT patients and their prevalence rates. Children from ethnic minorities displayed higher prevalent rates of RRT when 
Table 7.1. Data completeness for paediatric prevalent ERF population in 2012

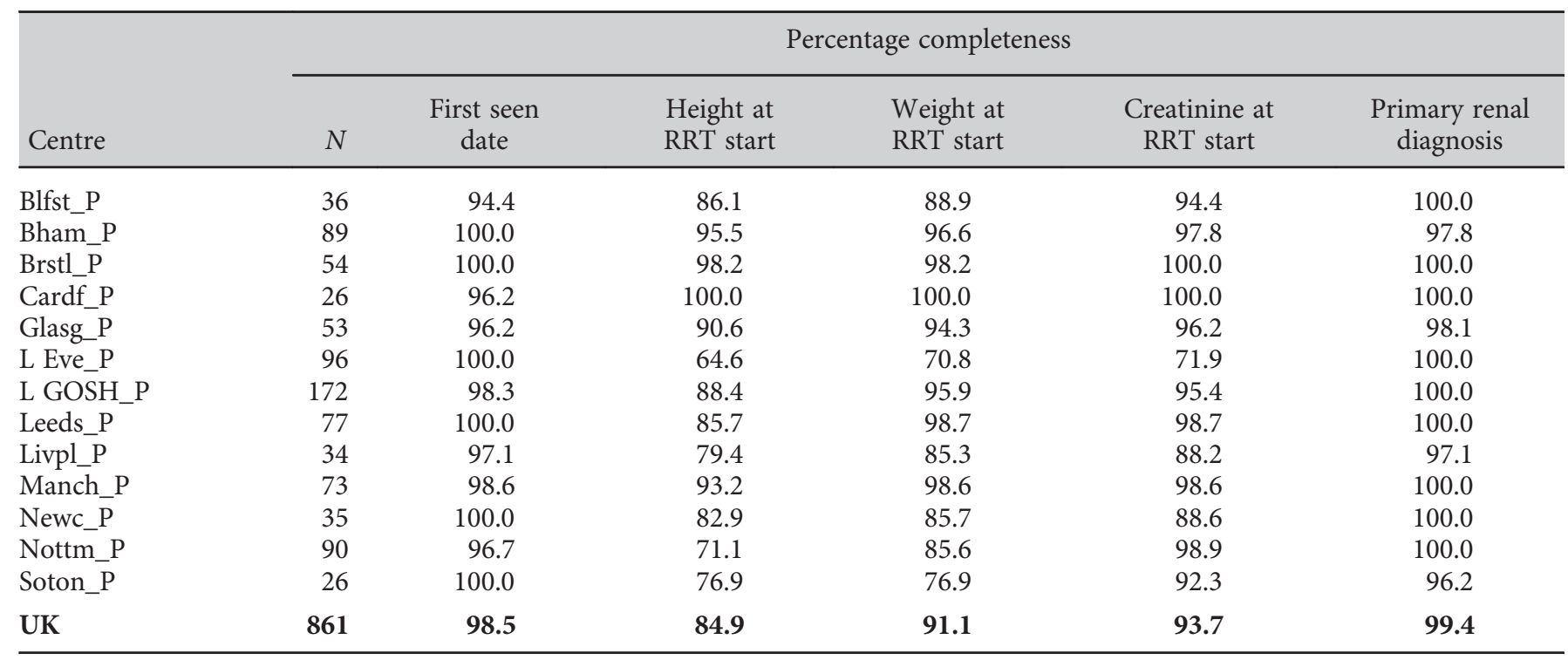

Table 7.2. The UK paediatric prevalent ERF population in 2012 , by age group and gender

\begin{tabular}{|c|c|c|c|c|c|c|c|}
\hline \multirow[b]{2}{*}{ Age group } & \multicolumn{2}{|c|}{ All patients } & \multicolumn{2}{|c|}{ Males } & \multicolumn{2}{|c|}{ Females } & \multirow[b]{2}{*}{ Ratio $\mathrm{M}: \mathrm{F}$} \\
\hline & $N$ & pmarp & $N$ & pmarp & $N$ & pmarp & \\
\hline $2-3.99$ years & 46 & 29.1 & 35 & 43.2 & 11 & 14.2 & 3.0 \\
\hline $4-7.99$ years & 140 & 46.1 & 86 & 55.4 & 54 & 36.5 & 1.5 \\
\hline $8-11.99$ years & 186 & 67.1 & 115 & 81.0 & 71 & 52.5 & 1.5 \\
\hline Under 16 years & 679 & 56.7 & 416 & 67.8 & 263 & 45.0 & 1.5 \\
\hline
\end{tabular}

pmarp - per million age related population

compared with White children, with South Asian children displaying the highest rates.

\section{Modality of treatment}

Current treatment modality in the prevalent paediatric population less than 16 years old in 2012 is displayed in figure 7.1. Of the $79 \%$ with a functioning transplant, $52 \%$ received a deceased donor transplantation and $48 \%$ a living donor transplantation.

The treatment modality in use at the start of RRT is displayed in figure 7.2. This shows that $48 \%$ of patients were treated with PD at the start of RRT whilst $29 \%$ of

Table 7.3. The UK paediatric prevalent ERF population by age and ethnic group in $2012^{\mathrm{a}}$

\begin{tabular}{|c|c|c|c|c|c|c|c|}
\hline \multirow[b]{2}{*}{ Age group } & \multicolumn{2}{|c|}{ White } & \multicolumn{2}{|c|}{ South Asian } & \multicolumn{2}{|c|}{ Black } & \multirow{2}{*}{$\frac{\text { Other }^{\mathrm{b}}}{N}$} \\
\hline & $N$ & pmarp & $N$ & pmarp & $N$ & pmarp & \\
\hline $0-3.99$ years & 47 & 18.2 & 13 & 61.6 & 0 & 0.0 & 3 \\
\hline $4-7.99$ years & 97 & 40.5 & 25 & 128.2 & 5 & 64.1 & 4 \\
\hline $8-11.99$ years & 140 & 54.7 & 29 & 139.1 & 8 & 95.9 & 13 \\
\hline $12-15.99$ years & 211 & 78.3 & 45 & 204.9 & 9 & 102.5 & 8 \\
\hline Under 16 years & 495 & 48.4 & 112 & 134.3 & 22 & 65.9 & 28 \\
\hline
\end{tabular}

pmarp - per million age related population

a ethnicity data missing in two children who are excluded from this table

bmarp not expressed for group 'Other', as heterogeneous group 


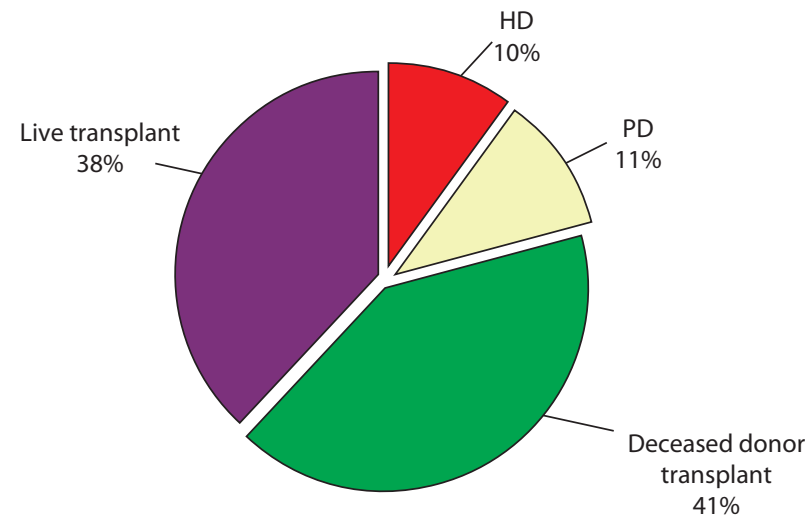

Fig. 7.1. RRT treatment used by prevalent paediatric patients $<16$ years old in 2012

patients were treated with HD. Twenty-three percent of children under 16 were reported to have received a pre-emptive transplant.

Further treatment modality analysis by age is shown in table 7.4 which demonstrates that in the under two year old age group no children received a transplant and that the majority of patients were being treated with $\mathrm{PD}$ $(57.1 \%)$. This contrasts with older children in the 12 to 15.99 year age group where $85 \%$ had a functioning graft and where similar proportions were on HD and PD. Subsequent analysis of RRT modality by gender and ethnicity showed no difference. However as absolute sub-group numbers are small, caution is needed in conducting any comparative analyses.

\section{Cause of ERF}

Table 7.5 and figure 7.3 show the diagnostic categories for the prevalent ERF population under 16 years in

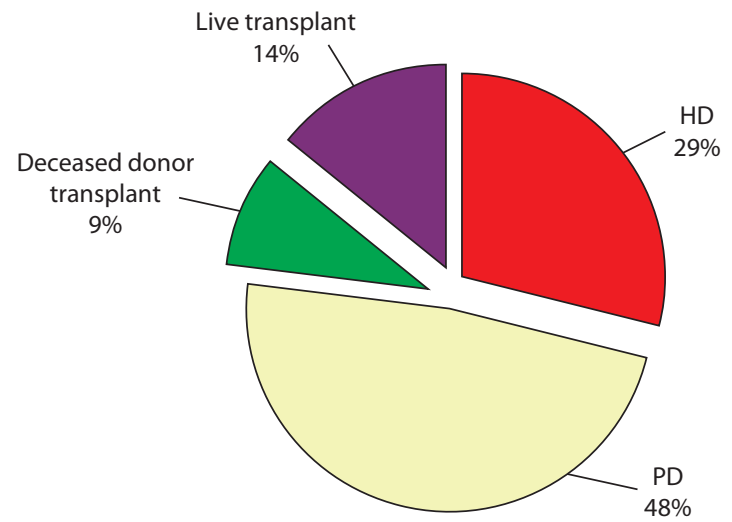

Fig. 7.2. Treatment modality at start of RRT in prevalent paediatric patients under 16 years of age in 2012

2012. There has been a marked improvement in data completeness in this category over the last few years with missing data falling to only $0.7 \%$ which was similar to that seen in the 2011 report [2]. Of the 679 patients, renal dysplasia \pm reflux remained the commonest condition causing ERF (33\%), whilst there were no documented patients with drug nephrotoxicity.

As for associated comorbidities at the onset of RRT, table 7.6 shows that congenital abnormalities were the commonest, reported in $9.4 \%$ of patients, followed by syndromic diagnosis at $8.8 \%$. Overall $65.5 \%$ of patients had no registered comorbidities, with $23 \%$ having one comorbidity listed, and $11.5 \%$ having two or more comorbidities. Centre analysis showed significant variation in reporting of registered comorbidities, with some centres, Cardiff (90\%), Birmingham (84\%), Glasgow $(80 \%)$ and GOSH $(79 \%)$ reporting no comorbidity in the majority of their patients, as compared to other centres

Table 7.4. Current treatment modality by age in the prevalent paediatric ERF population in 2012

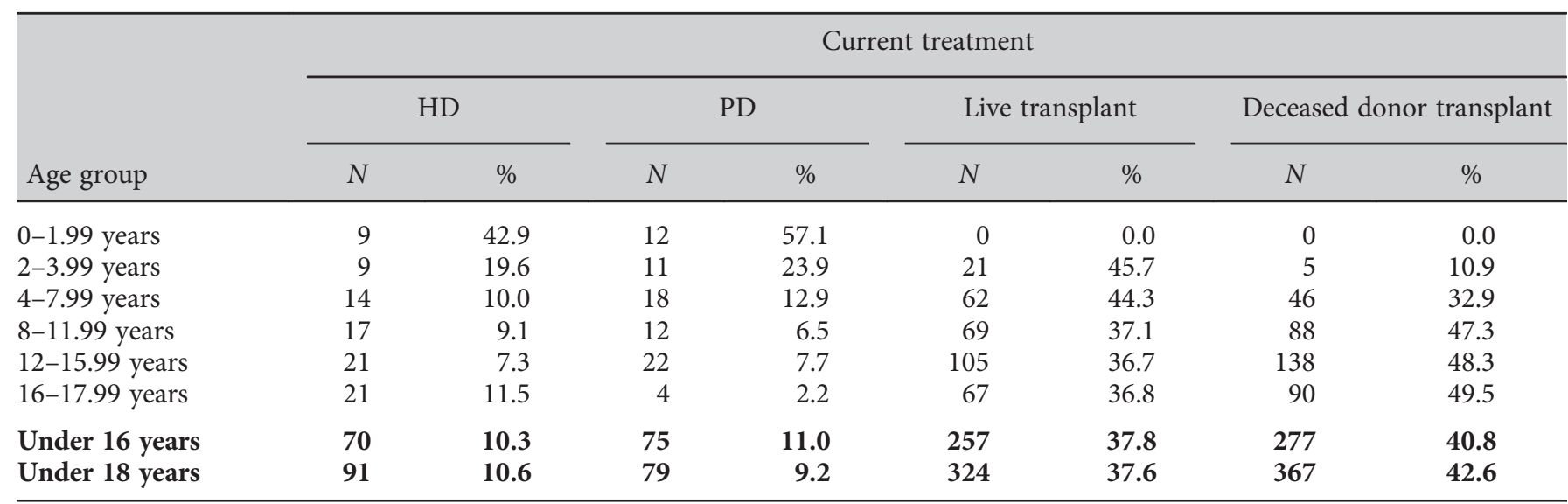


Table 7.5. Number, percentage and gender by primary renal disease as cause of ERF in the prevalent paediatric ERF population under 16 years in $2012^{*}$

\begin{tabular}{|c|c|c|c|c|c|}
\hline Diagnostic group & Total & $\%$ & Male & Female & $\mathrm{M}: \mathrm{F}$ ratio \\
\hline Obstructive uropathy & 126 & 18.6 & 118 & 8 & 14.8 \\
\hline Congenital nephrotic syndrome & 66 & 9.7 & 37 & 29 & 1.3 \\
\hline Tubulo-interstitial diseases & 50 & 7.4 & 23 & 27 & 0.9 \\
\hline Uncertain aetiology & 33 & 4.9 & 16 & 17 & 0.9 \\
\hline Metabolic & 20 & 2.9 & 8 & 12 & 0.7 \\
\hline Malignancy \& associated disease & 15 & 2.2 & 6 & 9 & 0.7 \\
\hline Missing & 5 & 0.7 & 1 & 4 & 0.3 \\
\hline Total & 679 & 100 & 416 & 263 & 1.6 \\
\hline
\end{tabular}

*In 2012 there were no patients with ERF secondary to 'drug nephrotoxicity'

which reported no comorbidity in a smaller proportion of patients, Bristol (27\%) and Manchester (42\%). This variation in reporting needs further investigation.

The UK incident paediatric ERF population in 2012

There were 117 patients under 18 years of age who commenced RRT at paediatric renal centres in 2012. As previously, the following analyses are restricted to the 108 patients who were under 16 years of age.

The incidence rate of RRT was 9.0 pmarp in 2012 . Patients commencing RRT in 2012 are displayed by age and gender in table 7.7.

Table 7.8 shows that the reported incidence of RRT has been rising since 1998, the highest incidence rates seen in

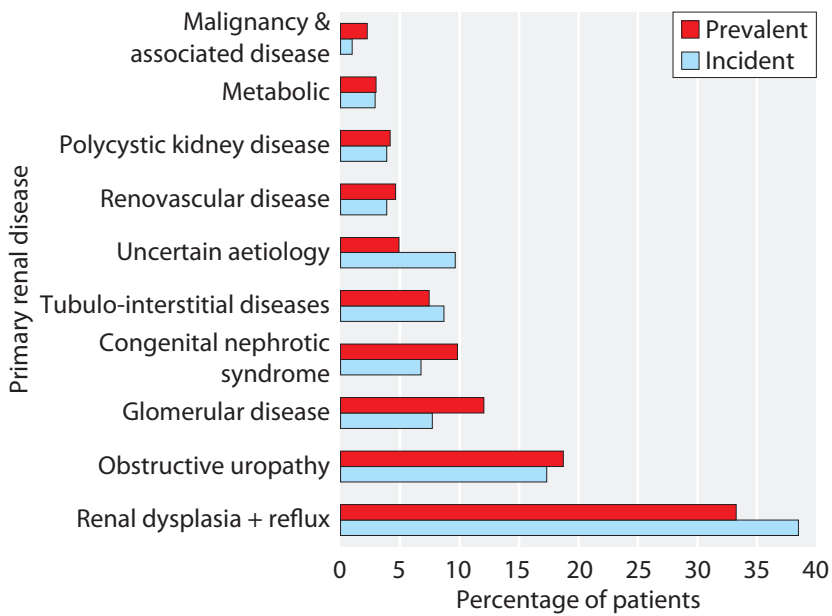

Fig. 7.3. Primary renal disease percentage in incident and prevalent paediatric ERF patients in 2012 for whom a causative diagnosis was reported the 12-15.99 year age group, with the $0-1.99$ year age group having the next highest rates.

\section{Trends in ERF demographics}

There were 1,656 children under 16 years of age who had received RRT in the UK over the 15-year period between 1998-2012. Analysis of ERF demographics for children less than 16 years of age over this period included 547 patients reported to the paediatric registry between 1998-2002, 536 between 2003-2007 and 573 between 2008-2012. Comparing the current 5-year

Table 7.6. Registered comorbidities at onset of RRT in prevalent paediatric patients aged $<16$ years with ERF in 2012

\begin{tabular}{lrc}
\hline Comorbidity & $N$ & $\begin{array}{c}\text { Percentage of all } \\
\text { RRT patients }\end{array}$ \\
\hline Cerebral palsy & 7 & 1.0 \\
Chromosomal abnormality & 17 & 2.5 \\
Congenital abnormality & 64 & 9.4 \\
Congenital heart disease & 14 & 2.1 \\
Consanguinity & 27 & 4.0 \\
Developmental delay & 54 & 8.0 \\
Diabetes & 3 & 0.4 \\
Family member with ERF & 19 & 2.8 \\
Liver disease & 12 & 1.8 \\
Malignancy & 4 & 0.6 \\
Neural tube defect & 4 & 0.6 \\
Prematurity & 54 & 8.0 \\
Psychological disorder & 6 & 0.9 \\
Syndromic diagnosis & 60 & 8.8 \\
No reported comorbidity & 445 & 65.5 \\
One reported comorbidity & 156 & 23.0 \\
Two or more comorbidities & 78 & 11.5
\end{tabular}


Table 7.7. The incident paediatric ERF population in the UK in 2012, by age group and gender

\begin{tabular}{|c|c|c|c|c|c|c|c|}
\hline \multirow[b]{2}{*}{ Age group } & \multicolumn{2}{|c|}{ All patients } & \multicolumn{2}{|c|}{ Male } & \multicolumn{2}{|c|}{ Female } & \multirow[b]{2}{*}{ M:F ratio } \\
\hline & $N$ & pmarp & $N$ & pmarp & $N$ & pmarp & \\
\hline $0-1.99$ years & 20 & 12.3 & 16 & 19.3 & 4 & 5.1 & 3.8 \\
\hline $2-3.99$ years & 12 & 7.6 & 8 & 9.9 & 4 & 5.2 & 1.9 \\
\hline $4-7.99$ years & 19 & 6.3 & 10 & 6.4 & 9 & 6.1 & 1.1 \\
\hline $8-11.99$ years & 19 & 6.9 & 10 & 7.0 & 9 & 6.7 & 1.1 \\
\hline $12-15.99$ years & 38 & 12.8 & 3 & 15.1 & 15 & 10.4 & 1.5 \\
\hline Under 16 years & 108 & 9.0 & 67 & 10.9 & 41 & 7.0 & 1.6 \\
\hline
\end{tabular}

pmarp - per million age related population

period with the two previous 5-year periods there has been an overall increase in the number of children treated with RRT, particularly in children aged under two years (table 7.9). The percentage of children on RRT who were from South Asian or Black ethnic backgrounds also increased during this period (table 7.10). The reported patient population at most paediatric renal centres has similarly grown in size since 1998-2002 (table 7.11).

Table 7.12 shows the number and percentage of children receiving RRT with each of the major reported

Table 7.8. Reported average incident rate by age group, in 5-year time periods, of children under 16 years of age commencing RRT

\begin{tabular}{lccc}
\hline & \multicolumn{3}{c}{ Per million age related population } \\
\cline { 2 - 4 } Age group & $1998-2002$ & $2003-2007$ & $2008-2012$ \\
\hline 0-1.99 years & 11.3 & 12.7 & 12.5 \\
2-3.99 years & 6.7 & 5.2 & 7.6 \\
4-7.99 years & 5.5 & 6.3 & 6.5 \\
8-11.99 years & 8.9 & 7.7 & 8.8 \\
12-15.99 years & 13.2 & 13.5 & 13.9 \\
Under 16 years & $\mathbf{9 . 1}$ & $\mathbf{9 . 3}$ & $\mathbf{9 . 9}$ \\
\hline
\end{tabular}

comorbidities over the last 15 years. Syndromic diagnoses (8.6\%), congenital abnormalities (8.0\%), developmental delay $(7.9 \%)$ were the most common reported comorbidities in 2008-2012, with little change in the percentage of children receiving RRT with a reported comorbidity over the last 15 years.

As for changes in modality at the start of RRT, figure 7.4 shows that the percentage of children who were using PD at the start of RRT has fallen from $54.7 \%$ in $1998-2002$ to $43.7 \%$ in $2008-2012$, whilst the percentage commencing RRT on HD increased from $23.1 \%$ in $1998-2002$ to $29.1 \%$ in $2008-2012$. During this period the overall percentage receiving a transplant at the start of RRT remained largely unchanged although living donation has risen from $7.1 \%$ in $1998-2002$ to $18.0 \%$ in 2008-2012, with a corresponding fall in deceased donor transplantation from $15.1 \%$ to $9.3 \%$ for the same time period.

Table 7.13 shows the diagnostic categories for 540 of the $546(98.9 \%)$ patients in 1998-2002, for 525 of the $536(97.9 \%)$ patients in 2003-2007 and 564 of the 573 (98.4\%) patients in 2008-2012 aged $<16$ years for whom a causative diagnosis was reported.

Table 7.9. Number and percentage of children who commenced RRT, by age group and 5 -year period, at start of RRT

\begin{tabular}{|c|c|c|c|c|c|c|c|}
\hline \multirow[b]{2}{*}{ Age group } & \multicolumn{2}{|c|}{ 1998-2002 } & \multicolumn{2}{|c|}{ 2003-2007 } & \multicolumn{2}{|c|}{ 2008-2012 } & \multirow{2}{*}{$\begin{array}{l}1998-2012 \\
\% \text { change }\end{array}$} \\
\hline & $N$ & $\%$ & $N$ & $\%$ & $N$ & $\%$ & \\
\hline $2-3.99$ years & 48 & 8.8 & 35 & 6.5 & 59 & 10.3 & 1.5 \\
\hline $4-7.99$ years & 81 & 14.8 & 87 & 16.2 & 92 & 16.1 & 1.2 \\
\hline $8-11.99$ years & 139 & 25.4 & 113 & 21.1 & 120 & 20.9 & -4.5 \\
\hline Under 16 years & 547 & & 536 & & 573 & & \\
\hline
\end{tabular}


Table 7.10. Number and percentage of children under 16 years who commenced RRT, by ethnicity and 5 -year period of starting RRT*

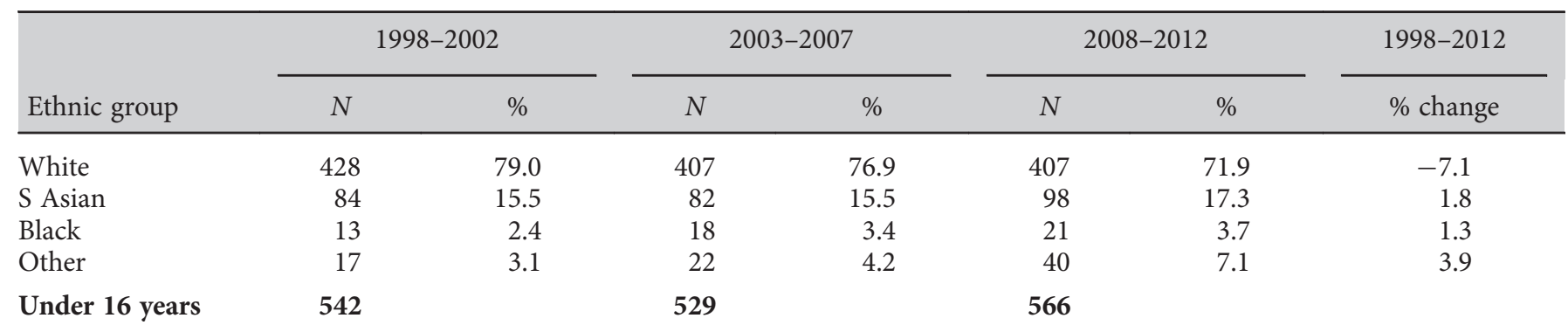

${ }^{*}$ Five children in 1998-2002, seven in 2003-2007 and seven in 2008-2012 with no ethnicity recorded are excluded from this table

Table 7.11. Number and percentage of children under 16 years reported to the UKRR, by renal centre and 5-year period of starting RRT*

\begin{tabular}{|c|c|c|c|c|c|c|c|}
\hline \multirow[b]{2}{*}{ Centre } & \multicolumn{2}{|c|}{ 1998-2002 } & \multicolumn{2}{|c|}{ 2003-2007 } & \multicolumn{2}{|c|}{ 2008-2012 } & \multirow{2}{*}{$\begin{array}{l}\text { 1998-2012 } \\
\% \text { change }\end{array}$} \\
\hline & $N$ & $\%$ & $N$ & $\%$ & $N$ & $\%$ & \\
\hline Blfst_P & 17 & 3.1 & 15 & 2.8 & 26 & 4.5 & 1.4 \\
\hline Bham_P & 51 & 9.3 & 55 & 10.3 & 66 & 11.5 & 2.2 \\
\hline Brstl_P & 36 & 6.6 & 40 & 7.5 & 29 & 5.1 & -1.5 \\
\hline Cardf_P & 17 & 3.1 & 24 & 4.5 & 17 & 3.0 & -0.1 \\
\hline Glasg_P & 40 & 7.3 & 36 & 6.7 & 43 & 7.5 & 0.2 \\
\hline L Eve_P & 61 & 11.2 & 45 & 8.4 & 62 & 10.8 & -0.4 \\
\hline L GOSH_P & 87 & 15.9 & 102 & 19.0 & 115 & 20.1 & 4.1 \\
\hline Leeds_P & 46 & 8.4 & 55 & 10.3 & 44 & 7.7 & -0.7 \\
\hline Livpl_P & 23 & 4.2 & 28 & 5.2 & 16 & 2.8 & -1.4 \\
\hline Manch_P & 58 & 10.6 & 44 & 8.2 & 54 & 9.4 & -1.2 \\
\hline Newc_P & 28 & 5.1 & 28 & 5.2 & 23 & 4.0 & -1.1 \\
\hline Nottm_P & 60 & 11.0 & 51 & 9.5 & 57 & 9.9 & -1.0 \\
\hline Soton_P & 22 & 4.0 & 13 & 2.4 & 21 & 3.7 & -0.4 \\
\hline Total $<16$ & 546 & & 536 & & 573 & & \\
\hline
\end{tabular}

* One child in 1998-2002 with unknown centre of RRT start was excluded from this table

Table 7.12. Trends in comorbidity at the start of RRT in the paediatric population under 16 years, by 5 -year period

\begin{tabular}{|c|c|c|c|c|c|c|c|}
\hline \multirow[b]{2}{*}{ Comorbidity } & \multicolumn{2}{|c|}{ 1998-2002 } & \multicolumn{2}{|c|}{ 2003-2007 } & \multicolumn{2}{|c|}{ 2008-2012 } & \multirow{2}{*}{$\begin{array}{l}\text { 1998-2012 } \\
\% \text { change }\end{array}$} \\
\hline & $N$ & $\%$ & $N$ & $\%$ & $N$ & $\%$ & \\
\hline Chromosomal abnormality & 18 & 3.3 & 17 & 3.2 & 9 & 1.6 & -1.7 \\
\hline Congenital abnormality & 43 & 7.9 & 49 & 9.1 & 46 & 8.0 & 0.2 \\
\hline Congenital heart disease & 15 & 2.7 & 13 & 2.4 & 13 & 2.3 & -0.5 \\
\hline Diabetes & 2 & 0.4 & 6 & 1.1 & 2 & 0.3 & 0.0 \\
\hline Family member with ERF & 21 & 3.8 & 16 & 3.0 & 12 & 2.1 & -1.7 \\
\hline Liver disease & 3 & 0.5 & 11 & 2.1 & 10 & 1.7 & 1.2 \\
\hline Malignancy & 7 & 1.3 & 5 & 0.9 & 2 & 0.3 & -0.9 \\
\hline Neural tube defect & 2 & 0.4 & 5 & 0.9 & 4 & 0.7 & 0.3 \\
\hline One reported comorbidity & 118 & 21.6 & 133 & 24.8 & 115 & 20.1 & -1.5 \\
\hline Two or more comorbidities & 60 & 11.0 & 56 & 10.4 & 59 & 10.3 & -0.7 \\
\hline
\end{tabular}




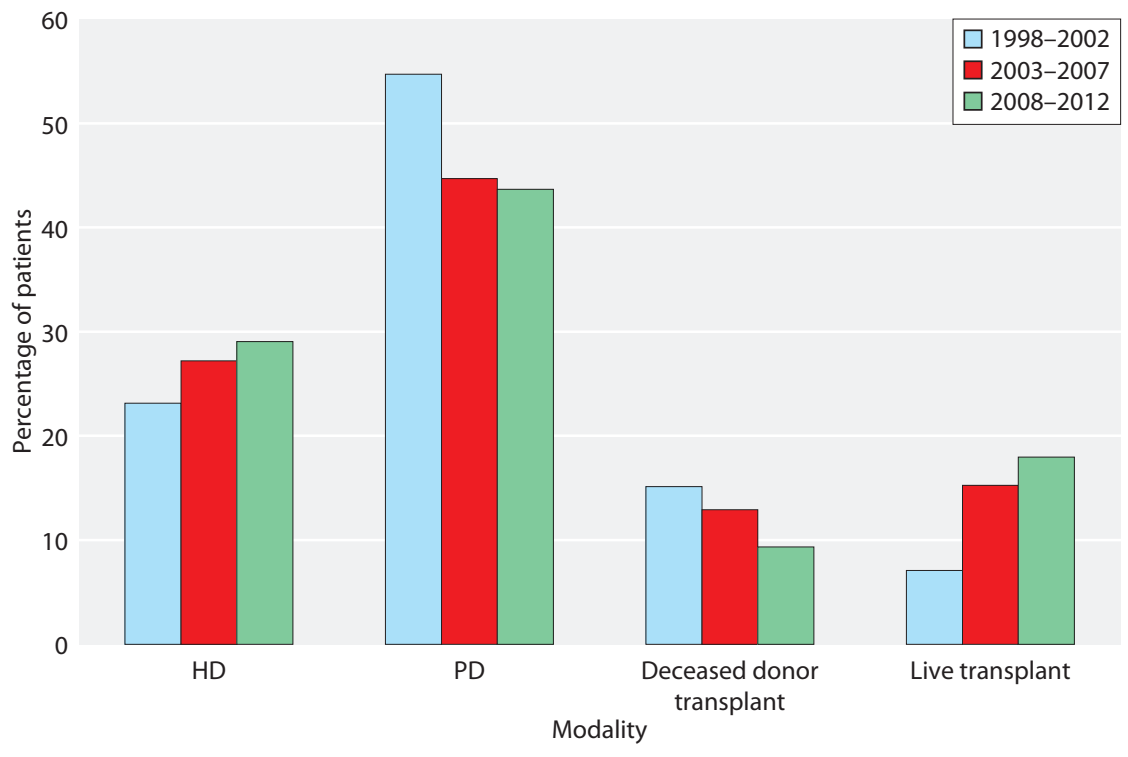

Fig. 7.4. Treatment modality at start of RRT by 5 -year time period
Overall there has been an increase in the percentage of children receiving RRT with renal dysplasia \pm reflux and interestingly also those with an uncertain aetiology between 1998-2002 and 2008-2012 although absolute numbers are very small (table 7.13 ).

\section{Pre-emptive transplantation}

Of a total of 1,656 patients who started RRT between 1998-2012, 460 patients were excluded from this analysis (94 patients were excluded due to being aged $<^{\prime \prime \prime}$ 3 months, and a further 366 patients were excluded due to being late presenters). Of 1,196 patients identified as being aged three months to $<16$ years and having started
RRT between 1998-2012, pre-emptive transplantation was seen to occur in $32.5 \%$ of patients and was significantly higher in males $(35.4 \%)$ than females $(27.8 \%)$, $\mathrm{p}=0.006$ (table 7.14). Ethnicity was also seen to be a significant factor, with children from Black (14.7\%) and South Asian (19.3\%) ethnicity having significantly lower rates of transplantation than their White counterparts $(35.8 \%), p<0.0001$. Analysis by age at start of RRT showed that as expected, the lowest rate of pre-emptive transplantation was in the three months to two year group $(5.1 \%)$, whilst children aged four to sixteen years had similar rates of pre-emptive transplantation. As for PRD, children with polycystic kidney disease (45\%)

Table 7.13. Number and percentage of children under 16 years for whom a primary renal diagnosis had been reported as a cause of ERF, by 5 year time period and observed change in proportion of patients in each diagnostic group*

\begin{tabular}{|c|c|c|c|c|c|c|c|}
\hline \multirow[b]{2}{*}{ Primary renal diagnosis } & \multicolumn{2}{|c|}{ 1998-2002 } & \multicolumn{2}{|c|}{ 2003-2007 } & \multicolumn{2}{|c|}{ 2008-2012 } & \multirow{2}{*}{$\begin{array}{r}\text { 1998-2012 } \\
\% \text { change }\end{array}$} \\
\hline & $N$ & $\%$ & $N$ & $\%$ & $N$ & $\%$ & \\
\hline Renal dysplasia \pm reflux & 149 & 27.6 & 182 & 34.7 & 181 & 32.1 & 4.5 \\
\hline Obstructive uropathy & 84 & 15.6 & 75 & 14.3 & 95 & 16.8 & 1.3 \\
\hline Glomerular disease & 130 & 24.1 & 105 & 20.0 & 96 & 17.0 & -7.1 \\
\hline Congenital nephrotic syndrome & 30 & 5.6 & 26 & 5.0 & 37 & 6.6 & 1.0 \\
\hline Tubulo-interstitial diseases & 38 & 7.0 & 48 & 9.1 & 44 & 7.8 & 0.8 \\
\hline Uncertain aetiology & 11 & 2.0 & 28 & 5.3 & 34 & 6.0 & 4.0 \\
\hline Renovascular disease & 26 & 4.8 & 13 & 2.5 & 20 & 3.5 & -1.3 \\
\hline Polycystic kidney disease & 15 & 2.8 & 17 & 3.2 & 20 & 3.5 & 0.8 \\
\hline Metabolic & 34 & 6.3 & 18 & 3.4 & 30 & 5.3 & -1.0 \\
\hline Malignancy \& associated disease & 7 & 1.3 & 9 & 1.7 & 6 & 1.1 & -0.2 \\
\hline Drug nephrotoxicity & 16 & 3.0 & 4 & 0.8 & 1 & 0.2 & -2.8 \\
\hline
\end{tabular}

\footnotetext{
* Six children in 1998-2002, eleven in 2003-2007 and nine in 2008-2012 with no PRD recorded are excluded from this table
} 
Table 7.14. Demographics of pre-emptive transplantation in children aged 3 months to 16 years in the UK between 19982012, analysed by 5-year time period, gender, ethnicity, age at start of RRT and primary renal diagnosis

\begin{tabular}{|c|c|c|}
\hline & $N$ & $\begin{array}{c}N(\%) \\
\text { pre-emptively } \\
\text { transplanted }\end{array}$ \\
\hline Total cohort analysed (1998-2012) & 1,196 & $389(32.5)$ \\
\hline $\begin{array}{l}\text { Time period } \\
1998-2002 \\
2002-2007 \\
2008-2012\end{array}$ & $\begin{array}{l}408 \\
388 \\
400\end{array}$ & $\begin{array}{l}107(26.2) \\
137(35.3) \\
145(36.3)\end{array}$ \\
\hline $\begin{array}{l}\text { Gender } \\
\text { Male } \\
\text { Female }\end{array}$ & $\begin{array}{l}742 \\
454\end{array}$ & $\begin{array}{l}263(35.4) \\
126(27.8)\end{array}$ \\
\hline $\begin{array}{l}\text { Ethnicity } \\
\text { Black } \\
\text { Other } \\
\text { South Asian } \\
\text { White }\end{array}$ & $\begin{array}{r}34 \\
49 \\
197 \\
899\end{array}$ & $\begin{array}{r}5(14.7) \\
16(32.7) \\
38(19.3) \\
322(35.8)\end{array}$ \\
\hline $\begin{array}{l}\text { Age at start of RRT } \\
3 \text { months- } 1.99 \text { years } \\
2-3.99 \text { years } \\
4-7.99 \text { years } \\
8-11.99 \text { years } \\
12-15.99 \text { years }\end{array}$ & $\begin{array}{l}117 \\
118 \\
211 \\
288 \\
462\end{array}$ & $\begin{aligned} 6 & (5.1) \\
32 & (27.1) \\
75 & (35.6) \\
101 & (35.1) \\
175 & (37.9)\end{aligned}$ \\
\hline $\begin{array}{l}\text { Primary renal diagnosis } \\
\text { Renal dysplasia + reflux } \\
\text { Glomerular disease } \\
\text { Obstructive uropathy } \\
\text { Congenital nephrotic syndrome } \\
\text { Tubulo-interstitial diseases } \\
\text { Metabolic } \\
\text { Polycystic kidney disease } \\
\text { Renovascular disease } \\
\text { Uncertain aetiology } \\
\text { Malignancy \& associated disease } \\
\text { Drug nephrotoxicity }\end{array}$ & $\begin{array}{r}387 \\
223 \\
219 \\
78 \\
73 \\
69 \\
40 \\
37 \\
25 \\
13 \\
12\end{array}$ & $\begin{aligned} 161 & (41.6) \\
26 & (11.7) \\
94 & (42.9) \\
5 & (6.4) \\
19 & (26.0) \\
29 & (42.0) \\
18 & (45.0) \\
15 & (40.5) \\
8 & (32.0) \\
1 & (7.7) \\
3 & (25.0)\end{aligned}$ \\
\hline
\end{tabular}

and obstructive uropathy $(42.9 \%)$ had the highest rates of pre-emptive transplantation, whilst those with congenital nephrotic syndrome $(6.4 \%)$ had the lowest rate. Over time there appears to have been a rise in pre-emptive transplantation rates, rising from $26.2 \%$ in 1998 2002 to $36.3 \%$ in $2008-2012, \mathrm{p}=0.004$ (table 7.14 ).

Transfer of patients to adult renal services in 2012

A total of 81 patients were reported by paediatric nephrology centres to have been transferred to adult renal services in 2012. The median age of patients transferred out was 18.1 years with an inter-quartile
Table 7.15. Modality, gender, ethnicity and primary renal diagnosis of patients transferred out of paediatric nephrology centres in 2012

\begin{tabular}{lrr}
\hline & $N$ & $\begin{array}{c}\% \\
\text { distribution }\end{array}$ \\
\hline Modality & & \\
HD & 11 & 13.6 \\
PD & 4 & 4.9 \\
Transplant & 66 & 81.5 \\
Gender & & \\
Female & 27 & 33.3 \\
Male & 54 & 66.7 \\
Ethnicity* & & \\
Black & 3 & 3.7 \\
Other & 2 & 2.5 \\
South Asian & 13 & 16.3 \\
White & 62 & 77.5 \\
Primary Renal Diagnosis* & & \\
Glomerular disease & 22 & 27.5 \\
Renal dysplasia \pm reflux & 21 & 26.3 \\
Obstructive uropathy & 12 & 15.0 \\
Congenital nephrotic syndrome & 6 & 7.4 \\
Uncertain aetiology & 6 & 7.5 \\
Metabolic & 4 & 5.0 \\
Tubulo-interstitial diseases & 3 & 3.8 \\
Drug nephrotoxicity & 2 & 2.4 \\
Polycystic kidney disease & 2 & 2.5 \\
Malignancy \& associated disease & 1 & 1.3 \\
Renovascular disease & 1 & 1.3 \\
\hline E & & \\
\hline
\end{tabular}

${ }^{*}$ Ethnicity missing in 1 patient, and PRD missing in 1 patient

range of 17.7 years to 18.5 years.

Table 7.15 shows that of the transferred patients $66.7 \%$ were male, with ethnic minorities constituting $22.5 \%$ of patients. The vast majority $(81.5 \%)$ had a functioning renal transplant at the time of transfer to an adult renal centre. Glomerular disease and renal dysplasia \pm reflux accounted for the primary renal diagnosis in over $50 \%$ of patients.

\section{Survival of children on RRT during childhood}

Of patients under the age of 16, 1,548 were identified as starting RRT between 1998 and 2011 at paediatric centres in the UK and were included in the survival analyses. At the census date (31st December 2012) there were a total of 103 deaths within the cohort on RRT at age $<16$, with a median follow up time of 3.6 years (range of one day to 15 years). Table 7.16 shows the survival hazard ratios after adjustment for age at start of RRT, gender and RRT modality, and highlights that children starting RRT at $0-1.99$ years 
Table 7.16. Survival hazard ratio during childhood for paediatric RRT patients aged $<16$ years in the UK adjusted for age at start of RRT, gender and RRT modality

\begin{tabular}{lccc}
\hline & $\begin{array}{c}\text { Hazard } \\
\text { ratio }\end{array}$ & $\begin{array}{c}\text { Confidence } \\
\text { interval }\end{array}$ & p-value \\
\hline Age & & & \\
$0-1.99$ years & 4.7 & $2.4-9.3$ & $<0.0001$ \\
2-3.99 years & 2.4 & $1.1-5.5$ & 0.03 \\
4-7.99 years & 1.6 & $0.7-3.7$ & 0.23 \\
8-11.99 years & 1.3 & $0.6-3.0$ & 0.48 \\
12-16 years & 1.0 & - & - \\
Gender & & & \\
Female & 1.3 & $0.9-1.9$ & 0.19 \\
Male & 1.0 & - & \\
RRT modality & & & $<0.0001$ \\
Dialysis & 6.3 & $3.4-11.7$ & \\
Transplant & 1.0 & - & \\
\hline
\end{tabular}

had the worst survival outcomes with a hazard ratio of 4.7 (CI 2.4-9.3, p < 0.0001) when compared to 12 16 year olds. Outcomes in the 2-3.99 age group were also significantly worse with a hazard ratio of 2.4 (CI $1.1-5.5, \mathrm{p}=0.03)$. Being on dialysis, as expected, was seen to lower survival significantly compared to having a functioning transplant with a hazard ratio of 6.3 (3.4-11.7, p $<0.0001)$. Figure 7.5 shows unadjusted Kaplan Meier survival probabilities. As the maximum age of follow up was restricted to 16 years, it was not possible to calculate 10 year survival probabilities for patients starting RRT aged $>8$ years, or 5 year survival probability for children starting RRT aged $>12$ years. This figure again highlights worse outcomes for those aged $0-1.99$ years.

\section{Mortality data in 2012}

There were nine deaths in renal paediatric centres in 2012 , eight children were aged $<16$ and one between 16-18 years at the time of death. In children aged $<16$ years with treated ERF, the reported mortality in 2012 in the UK at paediatric centres was 1.2\% (8/679). The median age at death was 10.8 years with a range of 0.2 years to 17.1 years. At the time of death, three children had received a kidney transplant and three were on dialysis (one haemodialysis and two PD).

Septicaemia was cited as a cause of death in three patients, two of which were associated with transplantation and one with peritoneal dialysis. One patient died as a result of chest complications during PD catheter insertion. Three further patients were receiving active palliative care at the time of death. A clear cause of death could not be identified in the two remaining patients who died in 2012.

\section{Discussion}

This report from the Paediatric Renal Registry has focussed on the current demography and the demographic trends over the past 15 years of the UK paediatric ERF population.

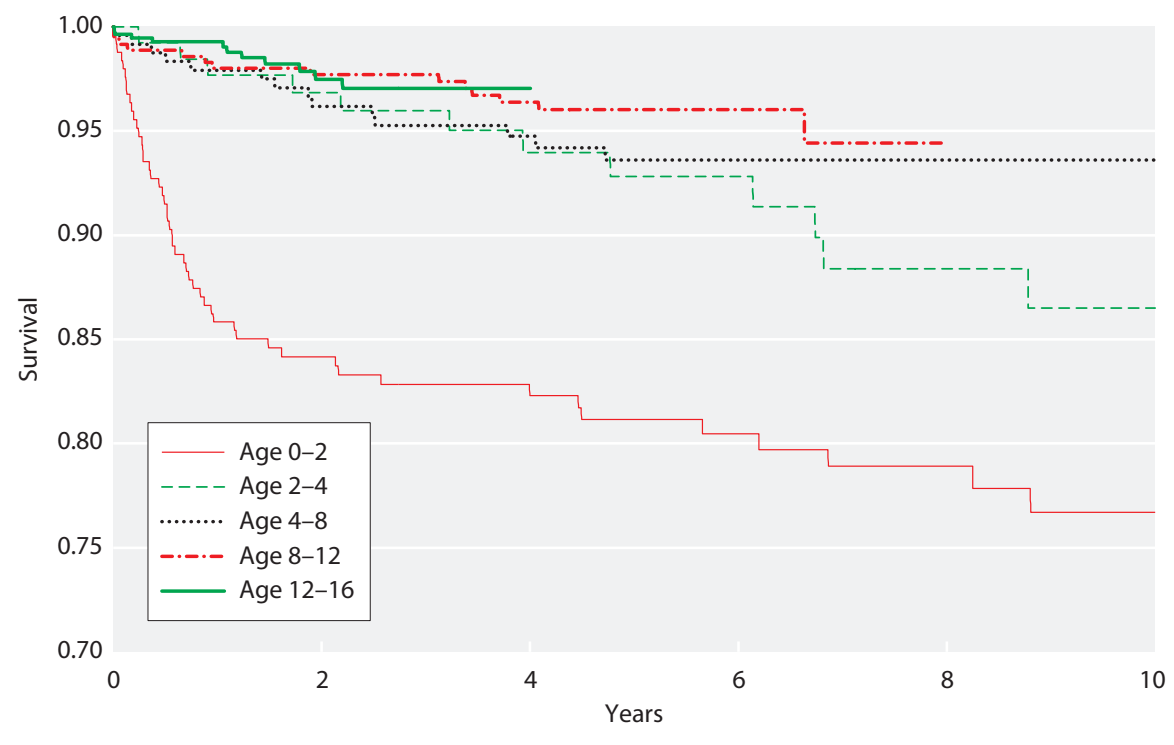

Fig. 7.5. Unadjusted $\mathrm{KM}$ in paediatric patients starting RRT between 1998 and 2011, by age at start 
This report includes 679 children and adolescents under 16 years of age, who were receiving RRT in 2012. The sub-section on the trends in demographics includes children and adolescents under 16 years of age on RRT; 546 from 1998-2002, 536 from 2003-2007 and 573 from 2008-2012.

\section{Data completeness}

The ongoing sustained effort to improve data accuracy must continue and the aim to move to full electronic annual returns from all centres remains. A revised data set (The NEW Paediatric Dataset) will be used in the near future to improve registry returns. These ongoing efforts to improve the quality and consistency of the data received will be rewarded by enabling enhanced interpretation of centre specific measures of clinical performance. Nearly $92 \%$ of data was submitted electronically from 11 of 13 paediatric nephrology centres in the UK. Data returns were complete for key data items and this together with improved checking and validation procedures within the registry contributed to continuing quality improvement.

\section{Incidence, prevalence and trends}

The incidence rate of RRT in the less than 16 year age group was 9.0 pmarp in 2012; this rate has been rising since 1998. The overall prevalence rate of RRT in the less than 16 year age group was 56.7 pmarp. The prevalence of RRT increased with age and was higher in males across all age groups. Overall, there was a continuing trend of increased prevalence of children on RRT with increased age, in keeping with improved survival with increasing age. This coupled with an increase in the number of children receiving RRT over the past 15 years has led to a steady increase in the prevalent ERF population.

\section{Treatment modality of ERF}

Peritoneal dialysis was the initial treatment modality for $48 \%$ of children at the start of treatment, $29 \%$ commenced $\mathrm{HD}$ and $23 \%$ received a pre-emptive transplant. Age influenced the modality of RRT with the majority of the under two's (57\%) receiving PD. Overall the majority of prevalent children (79\%) on RRT had a functioning transplant.

\section{Pre-emptive transplantation}

Over the last 15 years, pre-emptive transplantation was seen to occur in $32.5 \%$ of children under 16 years age. The rate of pre-emptive transplantation has increased over the past 15 years $(26.2 \%$ in $1998-2002$ to $36.3 \%$ in $2008-2012$ ). There were significantly lower rates of pre-emptive transplantation in girls and ethnic minorities and further detailed studies investigating these would be important.

\section{Comorbidities}

At the onset of RRT, $34.5 \%$ of patients had one or more associated comorbidities. This overall proportion of children with associated comorbidities has shown little change over the past 15 years. There continues to be significant variation in registered comorbidity rates between centres (10-73\%, data not shown); it is likely that this is influenced by different reporting practices between centres. This remains an area for further work from the registry and individual centres.

\section{Causes of ERF and observed trends 1998-2012}

As previously, renal dysplasia \pm reflux $(33 \%)$, glomerular disease (11.9\%) and obstructive uropathy (18.6\%) were the commonest listed aetiologies for children with ERF. These accounted for $63.5 \%$ of all patients for whom a primary diagnosis had been reported. Observation of trends over the 15-year period showed an increase in the percentage of children receiving RRT with renal dysplasia \pm reflux and those with unknown aetiology.

\section{Transfer out and survival data}

Data relating to transfer to adult renal services is included in the current report. The median age of transfer was 18.1 years. Of patients receiving RRT, 81.5\% transferred with a functioning renal transplant. There appears to be variation in practice between centres regarding transition and transfer out arrangements; it is also likely that variability exists in reporting of 'transfer out' timelines to the registry for patients being transitioned to adult centres. Unpublished results from a survey conducted by the paediatric subcommittee of the registry earlier this year highlighted that transition practices varied as to when children began the process (range: $15-16$ years); and when they were expecting to have successfully 'transitioned children' and transferred them out into adult services with some centres aiming for 16 years whilst others for 18 years. Consensus regarding terminology and process will facilitate future comparative interpretation.

Survival data of children on ERF during childhood who commenced RRT between 1998 and 2011 highlights the less favourable outcome for children less than two years of age. The data also highlights the significantly 
better survival of children with functioning transplants when compared to those on dialysis. Longer term survival data up to five years was available for those aged $<12$ years and 10 year survival data for those $<8$ years only. For the majority of children on RRT long term survival data needs follow up into young adulthood. This is the focus of an ongoing project of the UK Renal Registry.

Conflicts of interest: none

\section{References}

$1 \mathrm{http} / / /$ www.Ons.Gov.Uk/census

- 2 Pruthi R, O'Brien C, Casula A, Braddon F, Lewis M, Maxwell H, Tse Y, Inward C, Sinha MD. UK Renal Registry 15th Annual Report (December 2011): Chapter 4 Demography of the UK Paediatric Renal Replacement Therapy Population in 2011. Nephron Clin Pract. 2013;123(suppl 1): 81-92. doi: 10.1159/000353323 